\title{
Pendidikan Seksual Anak Usia Dini dalam Persfektif Hukum Islam
}

\author{
Amirudin $^{1}$, Ine Nirmala ${ }^{2}$
}

Fakultas Agama Islam

Universitas Singaperbangsa Karawang

JI. HS. Ronggowaluyo Telukjambe Telp. (0267) 6411177 Ext 306.

Fax (0267) 641367 Karawang 41361

Email: ${ }^{1}$ amirudin@staff.unsika.ac.id, ${ }^{2}$ ine.nirmala@staff.unsika.ac.id

\begin{abstract}
Abstrak
Penelitian ini dilatarbelakangi oleh banyaknya fenomena memprihatinkan yang terjadi di masyarakat, yakni kejahatan seksual yang makin banyak terjadi. Korban kejahatan seksual terjadi pada anak-anak di bawah umur. Padahal kewajiban orang tua terhadap anak tidak sebatas mencukupi kebutuhan lahir dan batin anak saja, melaikan membekali anak dengan ilmu diantaranya keimanan atau akidah, Alquran, fiqih, ibadah dan keterampilan. Melihat betapa pentingnya pendidikan seksual anak maka kami mengangkat tema penelitian tentang pendidikan anak seksual anak usia dini dalam perspektif Islam. Metode yang digunakan dalam penelitian ini adalah metode kepustakaan (library research). Pendekatan dalam penelitian ini menggunakan pendekatan deskriptif analistis, yaitu dengan cara meneliti dan menganalisis tentang pendidikan seksual bagi anak usia dini dari berbagai sumber secara terurai kemudian mendeskripsikannya. Sedangkan sumber data berasal dari Alquran, kitab-kitab tafsir dan hadist, buku-buku tentang pendidikan anak dan kamus bahasa Arab.
\end{abstract}

Kata Kunci: pendidikan seksual anak, perspektif islam

\section{Abstract}

This research is motivated by a worrying phenomenon that occurs in the community, which is a lot of sexual occurrences. Sexy crime victims occur in minors. Parents for children are not limited to just fulfilling the birth and inner needs of children, but equipping children with the knowledge of faith or creed, Qur'an, jurisprudence, worship, and skills. Seeing the importance of education, children, and us, raising themes about the education of children, children, early lessons in Islam. The method used in this study is the library method. The 
approach in this study uses a descriptive analytic approach, namely by analyzing and analyzing sexual education for children from various sources. While the data comes from the Alquran, tafsir and hadith books, books about children's education and Arabic dictionaries.

Keywords: child sexual education, Islamic perspective

\section{Pendahuluan}

Dalam memberikan pendidikan seksual pada anak jangan menunggu sampai anak bertanya mengenai seksual. Sebaiknya pendidikan seksual diberikan dengan terencana, sesuai dengan keadaan dan kebutuhan anak, baik pada saat anak menjelang remaja dimana proses kematangan fisik, maupun mentalnya mulai timbul dan berkembang kearah kedewasaan.

Pendidikan seksual pada anak usia dini dengan rentang umur antara $0-6$ tahun sangat penting untuk diberikan, karena merupakan bekal anak dalam memiliki konsep diri yang baik ketika mereka dewasa. Saat ini pendidikan seksual mulai digalakan di sekolahsekolah mulai dari jenjang pendidikan anak usia dini. Konsep pendidikan seksual untuk anak usia dini yang diberikan berupa pengetahuan tentang jenis kelamin, pengetahuan mengenai dirinya, pencegahan dari kekerasan seksual, dan konsep diri yang positif.

Seksualitas tumbuh dan berkembang dengan pesat, oleh karena itu di antara prinsip pendidikan kepribadian dalam Islam mengajarkan bahwa seorang anak harus dididik dan diperlakukan sesuai dengan jenis kelaminnya. Dalam Alquran telah dikemukakan bagaimana cara mendidik anak secara detail, bahkan sejak anak dalam sulbi ayah. Pembahasan mengenai seksual masih danggap tabu dikalangan masyarakat. Masyarakat beranggapan bahwa pendidikan seksual belum pantas diberikan kepada anak usia dini. Padahal pendidikan seksual yang diberikan sejak dini sangat berpengaruh dalam kehidupan anak ketika ia memasuki masa remaja. Untuk menghadapi masa depannya, pengetahuan dan informasi tentang seksual sangat penting untuk diketahui. Informasi tentang seksual sebaiknya didapatkan dari orangtua, guru atau sumber informasi lainnya. 


\section{Pembahasan}

\section{Penerapan Pendidikan Seks Sejak Dini}

Menurut Zulia Ilmawati, Psikolog Pemerhati Masalah Anak dan Remaja dalam tulisannya Pendidikan Seks Untuk Anak-anak, ada beberapa pokok pendidikan seks (sex education) secara praktis yang dapat diterapkan pada anak sejak dini yaitu:

\section{A. Menanamkan Jiwa Maskulinitas pada Anak Laki-laki dan Jiwa Feminitas pada Anak Perempuan.}

Mencampurkan anak laki-laki dan anak perempuan pada usia dini akan menimbulkan kerusakan dan cacat pada cara pandang, sifat, dan perbuatan pada kedua jenis tersebut. Karena itu, penting agar dipahami oleh anak laki-laki, agar dia tidak memakai pakaian saudara perempuannya, atau tidak boleh mengenakan anting-anting di telinganya, atau tidak boleh memakai gelang, karena semua itu berlaku untuk wanita, bukan untuk laki-laki. Demikian pula halnya dikatakan terhadap anak wanita terkait dengan perbuatan dan sifat-sifat saudara laki-lakinya. Oleh karena itu orang tua harus memberikan pakaian yang sesuai dengan jenis kelamin anak, sehingga mereka terbiasa untuk berprilaku sesuai dengan fitrahnya. Mereka juga harus diperlakukan sesuai dengan jenis kelaminnya. Ibnu Abbas ra. berkata: Rasulullah saw. melaknat laki-laki yang berlagak wanita dan wanita yang berlagak meniru laki-laki. (H.R. Al-Bukhari).

\section{B. Mendidik Menjaga Kebersihan Alat Kelamin.}

Mengajari anak untuk menjaga kebersihan alat kelamin selain agar bersih dan sehat sekaligus juga mengajari anak tentang najis. Anak juga harus dibiasakan untuk buang air pada tempatnya (toilet training). Dengan cara ini akan terbentuk pada diri anak sikap hatihati, mandiri, mencintai kebersihan, mampu menguasai diri, disiplin, dan sikap moral yang memperhatikan tentang etika sopan santun dalam melakukan hajat.

Setiap orang yang hendak menunaikan hajatnya, buang air besar atau air kecil, maka hendaklah ia mengikuti 10 adab berikut ini.

1. Menutup diri dan menjauh dari manusia ketika buang hajat.

Dari Jabir bin 'Abdillah radhiyallahu 'anhu, beliau berkata,

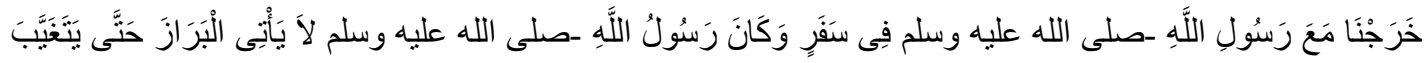

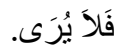


"Kami pernah keluar bersama Rasulullah shallallahu 'alaihi wa sallam ketika safar, beliau tidak menunaikan hajatnya di daerah terbuka, namun beliau pergi ke tempat yang jauh sampai tidak nampak dan tidak terlihat.

2. Tidak membawa sesuatu yang bertuliskan nama Allah.

Seperti memakai cincin yang bertuliskan nama Allah dan semacamnya. Hal ini terlarang karena kita diperintahkan untuk mengagungkan nama Allah dan ini sudah diketahui oleh setiap orang secara pasti. Allah Ta'ala berfirman,

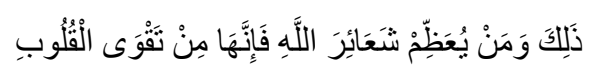

"Demikianlah (perintah Allah). Dan barangsiapa mengagungkan syi'ar-syi'ar Allah, maka sesungguhnya itu timbul dari ketakwaan hati." (QS. Al Hajj: 32)

Ada sebuah riwayat dari Anas bin Malik, beliau mengatakan,

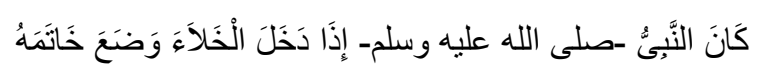

"Rasulullah shallallahu 'alaihi wa sallam biasa ketika memasuki kamar mandi, beliau meletakkan cincinnya." Akan tetapi hadits ini adalah hadits munkar yang diingkari oleh banyak peneliti hadits. Namun memang cincin beliau betul bertuliskan "Muhammad Rasulullah".

Syaikh Abu Malik hafizhohullah mengatakan, "Jika cincin atau semacam itu dalam keadaan tertutup atau dimasukkan ke dalam saku atau tempat lainnya, maka boleh barang tersebut dimasukkan ke WC. Imam Ahmad bin Hambal mengatakan, "Jika ia mau, ia boleh memasukkan barang tersebut dalam genggaman tangannya." Sedangkan jika ia takut barang tersebut hilang karena diletakkan di luar, maka boleh masuk ke dalam kamar mandi dengan barang tersebut dengan alasan kondisi darurat."

3. Membaca basmalah dan meminta perlindungan pada Allah (membaca ta'awudz) sebelum masuk tempat buang hajat.

Ini jika seseorang memasuki tempat buang hajat berupa bangunan. Sedangkan ketika berada di tanah lapang, maka ia mengucapkannya di saat melucuti pakaiannya.

Dalil dari hal ini adalah sabda Nabi shallallahu 'alaihi wa sallam,

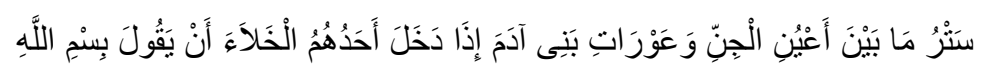

"Penghalang antara pandangan jin dan aurat manusia adalah jika salah seorang di antara mereka memasuki tempat buang hajat, lalu ia ucapkan "Bismillah"."

Dari Anas bin Malik, beliau mengatakan,

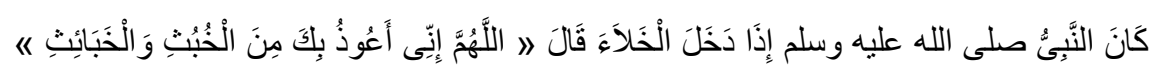


"Rasulullah shallallahu 'alaihi wa sallam ketika memasuki jamban, beliau ucapkan: Allahumma inni a'udzu bika minal khubutsi wal khobaits (Ya Allah, aku berlindung kepadaMu dari setan laki-laki dan setan perempuan".

4. Masuk ke tempat buang hajat terlebih dahulu dengan kaki kiri dan keluar dari tempat tersebut dengan kaki kanan

Dalam perkara yang baik-baik seperti memakai sandal dan menyisir, maka kita dituntun untuk mendahulukan yang kanan. Sebagaimana terdapat dalam hadits,

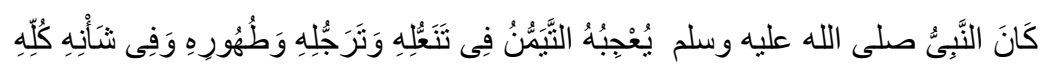

"Nabi shallallahu 'alaihi wa sallam lebih suka mendahulukan yang kanan ketika memakai sandal, menyisir rambut, ketika bersuci dan dalam setiap perkara (yang baik-baik)."

Dari hadits ini, Syaikh Ali Basam mengatakan, "Mendahulukan yang kanan untuk perkara yang baik, ini ditunjukkan oleh dalil syar'i, dalil logika dan didukung oleh fitrah yang baik. Sedangkan untuk perkara yang jelek, maka digunakan yang kiri. Hal inilah yang lebih pantas berdasarkan dalil syar'i dan logika."

Asy Syaukani rahimahullah mengatakan, "Adapun mendahulukan kaki kiri ketika masuk ke tempat buang hajat dan kaki kanan ketika keluar, maka itu memiliki alasan dari sisi bahwa Nabi shallallahu 'alaihi wa sallam lebih suka mendahulukan yang kanan untuk hal-hal yang baik-baik. Sedangkan untuk hal-hal yang jelek (kotor), beliau lebih suka mendahulukan yang kiri. Hal ini berdasarkan dalil yang sifatnya global."

5. Tidak menghadap kiblat atau pun membelakanginya.

Dari Abu Ayyub Al Anshori, Nabi shallallahu ‘alaihi wa sallam bersabda,

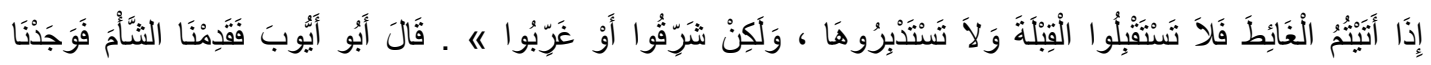

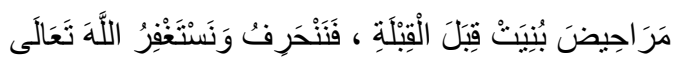

"Jika kalian mendatangi jamban, maka janganlah kalian menghadap kiblat dan membelakanginya. Akan tetapi, hadaplah ke arah timur atau barat."

Abu Ayyub mengatakan, "Dulu kami pernah tinggal di Syam. Kami mendapati jamban kami dibangun menghadap ke arah kiblat. Kami pun mengubah arah tempat tersebut dan kami memohon ampun pada Allah Ta'ala." Yang dimaksud dengan "hadaplah arah barat dan timur" adalah ketika kondisinya di Madinah. Namun kalau kita berada di Indonesia, maka berdasarkan hadits ini kita dilarang buang hajat dengan menghadap arah barat dan timur, dan diperintahkan menghadap ke utara atau selatan.

6. Terlarang berbicara secara mutlak kecuali jika darurat.

Dalilnya adalah hadits dari Ibnu 'Umar radhiyallahu 'anhuma, beliau berkata, 


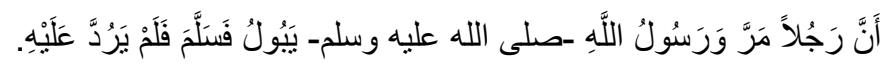

"Ada seseorang yang melewati Rasulullah shallallahu 'alaihi wa sallam dan beliau sedang kencing. Ketika itu, orang tersebut mengucapkan salam, namun beliau tidak membalasnya."

Syaikh Ali Basam mengatakan, "Diharamkan berbicara dengan orang lain ketika buang hajat karena perbuatan semacam ini adalah suatu yang hina, menunjukkan kurangnya rasa malu dan merendahkan murua'ah (harga diri)." Kemudian beliau berdalil dengan hadits di atas.

Syaikh Abu Malik mengatakan, "Sudah kita ketahui bahwa menjawab salam itu wajib. Ketika buang hajat Nabi shallallahu 'alaihi wa sallam meninggalkannya, maka ini menunjukkan diharamkannya berbicara ketika itu, lebih-lebih lagi jika dalam pembicaraan itu mengandung dzikir pada Allah Ta'ala. Akan tetapi, jika seseorang berbicara karena ada suatu kebutuhan yang mesti dilakukan ketika itu, seperti menunjuki jalan pada orang (ketika ditanya saat itu, pen) atau ingin meminta air dan semacamnya, maka dibolehkan saat itu karena alasan darurat."

7. Tidak buang hajat di jalan dan tempat bernaungnya manusia.

Dalilnya adalah hadits dari Abu Hurairah, Nabi shallallahu 'alaihi wa sallam bersabda.

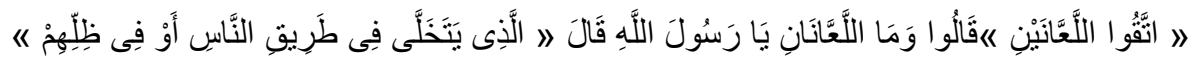

"Hati-hatilah dengan al la'anain (orang yang dilaknat oleh manusia)!" Para sahabat bertanya, "Siapa itu al la'anain (orang yang dilaknat oleh manusia), wahai Rasulullah?" Beliau bersabda, "Mereka adalah orang yang buang hajat di jalan dan tempat bernaungnya manusia."

8. Tidak buang hajat di air yang tergenang.

Dalilnya adalah hadits Jabir bin 'Abdillah, beliau berkata,

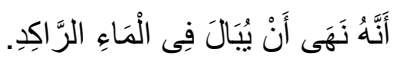

"Rasulullah shallallahu 'alaihi wa sallam melarang kencing di air tergenang."

Salah seorang ulama besar Syafi'iyah, Ar Rofi'i mengatakan, "Larangan di sini berlaku untuk air tergenang yang sedikit maupun banyak karena sama-sama dapat mencemari." Dari sini, berarti terlarang kencing di waduk, kolam air dan bendungan karena dapat menimbulkan pencemaran dan dapat membawa dampak bahaya bagi yang lainnya. Jika kencing saja terlarang, lebih-lebih lagi buang air besar. Sedangkan jika airnya adalah air yang mengalir (bukan tergenang), maka tidak mengapa. 
8. Memperhatikan adab ketika istinja' (membersihkan sisa kotoran setelah buang hajat, alias cebok), di antaranya sebagai berikut.

a. Tidak beristinja' dan menyentuh kemaluan dengan tangan kanan.

b. Beristinja' bisa dengan menggunakan air atau menggunakan minimal tiga batu (istijmar).

Beristinja' dengan menggunakan air lebih utama daripada menggunakan batu sebagaimana menjadi pendapat Sufyan Ats Tsauri, Ibnul Mubarok, Imam Asy Syafi'i, Imam Ahmad dan Ishaq. Alasannya, dengan air tentu saja lebih bersih.

c. Memerciki kemaluan dan celana dengan air setelah kencing untuk menghilangkan was-was.

d. Mengucapkan do'a "ghufronaka" setelah keluar kamar mandi.

Oleh karenanya, ia pun berdoa pada Allah agar dihapuskan dosa-dosanya sebagaimana Allah mempermudah kotoran-kotoran badan tersebut keluar."

Cara lain untuk mendidik anak dalam menjaga kebersihan alat kelamin adalah khitanan. Khitan secara bahasa artinya memotong. Secara terminologis artinya memotong kulit yang menutupi alat kelamin lelaki (penis). Dalam bahasa Arab khitan juga digunakan sebagai nama lain alat kelamin lelaki dan perempuan seperti dalam hadist yang mengatakan "Apabila terjadi pertemuan dua khitan, maka telah wajib mandi" (H.R. Muslim, Tirmidzi dII). Dalam agama Islam, khitan merupakan salah satu media pensucian diri dan bukti ketundukan kita kepada ajaran agama. Dalam hadist Rasulullah s.a.w. bersabda:"Kesucian (fitrah) itu ada lima: khitan, mencukur bulu kemaluan, mencabut bulu ketiak, memendekkan kumis dan memotong kuku" (H.R. Bukhari Muslim).

Dalam fikih Islam, hukum khitan dibedakan antara untuk lelaki dan perempuan. Para ulama berbeda pendapat mengenai hukum khitan baik untuk lelaki maupun perempuan.

Seiykh al-Qardhawi berkata, di antara fiqh almaqosyid (kebaikan) khitan lelaki adalah :

a. Mencegah kotoran dan tempat pembiakan kuman pada zakar.

b. Terhindarnya zakar dari terkena penyakit kelamin seperti sifilis

c. Quluf atau foreskin zakar akan mudah mengalami radang atau melecet

d. Zakar akan kurang risiko kepada penyakit zakar seperti pembengkakan atau kanker.

e. Memaksimumkan kepuasan seks ketika jima' (hubungan seks) 


\section{MENANAMKAN RASA MALU KEPADA ANAK}

Rasa malu harus ditanamkan kepada anak sejak dini. Jangan biasakan anak-anak, bertelanjang di depan orang lain; misalnya ketika keluar kamar mandi, berganti pakaian, dan sebagainya. Dan membiasakan anak untuk selalu menutup auratnya.

\section{Pengertian Al Haya'/Malu}

Kata “malu" dalam bahasa Arab adalah آلْحَيَاءُ (al-hayaa'). Malu adalah satu kata yang mencakup perbuatan menjauhi segala apa yang dibenci.

Al-Junaid rahimahullâh berkata, "Rasa malu yaitu melihat kenikmatan dan keteledoran sehingga menimbulkan suatu kondisi yang disebut dengan malu. Hakikat malu ialah sikap yang memotivasi untuk meninggalkan keburukan dan mencegah sikap menyia-nyiakan hak pemiliknya. Rasa malu (al-haya') ialah suatu sifat yang alami dalam diri manusia, yang menjadikannya merasa tidak enak ketika dia melakukan perbuatan jelek dan haram. Dia dapat mencegah dirinya untuk tidak melakukan perbuatan terlarang, karena adanya perasaan yang alami dan fitriah itu.

Begitu pula dengan rasa malu, seseorang memelihara hak ayah, ibu, anak, guru, dan setiap orang yang berbuat baik kepadanya. Dia tidak berkhianat, mengingkari janji, atau menolak orang yang meminta pertolongan kepadanya. Dengan perasaan malu pula seseorang tidak akan melakukan perbuatan keji dan perbuatan yang tidak sesuai dengan dirinya.

Sungguh rasa malu dapat dijadikan tindakan pencegahan terhadap segala macam kerusakan. la lebih bermanfaat ketimbang ratusan peraturan dan penjaga. Sesungguhnya orang-orang yang mencintai kebaikan masyarakat, menginginkan hilangnya keonaran, harus berupaya agar sifat rasa malu ini tidak lepas dari anggota masyarakat mereka. Bahkan mereka harus menghidupkan dan menumbuhkannya. Tugas utama dan mulia ini tertumpu pada pundak para bapak dan ibu, guru, dan juga semua kaum Muslimin.

Dari definisi di atas dapat disimpulkan bahwa malu adalah akhlak (perangai) yang mendorong seseorang untuk meninggalkan perbuatan-perbuatan yang buruk dan tercela, sehingga mampu menghalangi seseorang dari melakukan dosa dan maksiat serta mencegah sikap melalaikan hak orang lain.

\section{Hukum memiliki sifat malu.}

Berkaitan dengan hukum memiliki sifat malu adalah sebagaimana sabda Nabi SAW.

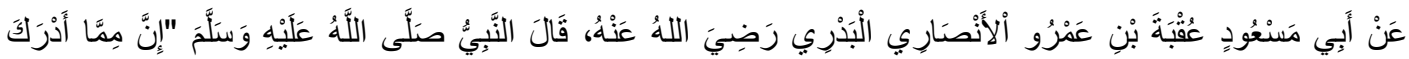

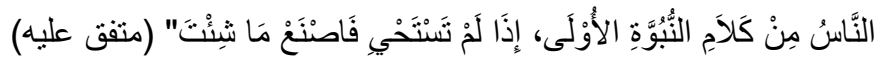


Dari Abu Mas'ud Uqbah bin Amru Al-Anshari Al-Badri ra berkata, bahwa Rasulullah SAW bersabda, 'Sesungguhnya sebagian dari apa yang telah dikenal orang dari ungkapan kenabian yang pertama adalah, 'Jika kamu tidak malu, berbuatlah sekehendakmu.' (HR. Bukhari Muslim)

Terdapat perbedaan pendapat berkenaan dengan hukum bersifat al-haya', apakah hukumnya wajib (menjadi suatu keharusan), ataukah tidak? Perbedaan pendapat ini berpangkal dari pemahaman terhadap hadits di atas sebagai berikut :

Pendapat pertama, adalah pendapat yang mengatakan bahwa sifat al-haya' merupakan suatu keharusan (wajib). Hal ini didasarkan pada sabda Rasulullah SAW dalam hadits di atas, "Jika kamu tidak malu, berbuatlah sekehendakmu.". Ulama mengatakan bahwa ungkapan tersebut bertujuan sebagai teguran keras dan celaan terhadap orang yang tidak memiliki rasa malu. Karena jika orang sudah tidak memiliki rasa malu, maka berbuatlah sekehendaknya; baik atau buruk, bermanfaat atau justru bermadharat, dsb. Dan berbuat sesuai kehendak hati yang diiringi dengan hawa nafsu sudah barang tentu menjadi perbuatan dosa. Karena salah satu fungsi iman adalah mengontrol hawa nafsu.

Pendapat kedua, adalah pendapat yang memengatakan bahwa sifat al-haya' adalah tidak wajib. Hal ini juga didasarkan pada hadits di atas, hanya saja mereka berpendapat bahwa yang dimaksud dengan sabda Nabi SAW 'berbuatlah sesukamu'; maksudnya adalah mubah (boleh) untuk berbuat sekehendaknya. Dan selama perbuatan sekehdaknya tersebut tidak melanggar syariah, maka hukumnya masih boleh-boleh saja.

Dari kedua pendapat tersebut, baik Ibnu Qayim al-Jauzi dalam Tahdzib Madarijis Salikin maupun Syekh Musthafa Dieb AI-Bugha dalam AI-Wafi, merajihkan pendapat yang pertama; yaitu bahwa sabda nabi SAW "berbuatlah sekehendakmu" sebagai sebuah teguran keras dan celaan. Oleh karenanya, setiap muslim harus menghiasi dirinya dengan sifat al-haya' ini.

\section{Macam-macam sifat malu.}

Semua perbuatan yang dianggap oleh akal dan agama sebagai sesuatu yang jelek dan tidak masuk akal, patut mendapatkan rasa malu bila kita melakukannya. Sehingga dengan begitu, kita tidak mendekat kepada perbuatan tersebut, dan kita menjadi orang yang terpuji.Rasa malu seperti itu terbagi menjadi dua bagian :

a. Rasa malu terhadap manusia, yakni seseorang meninggalkan suatu perbuatan yang kurang terpuji karen atakut dilihat oleh orang lain, sehingga dia merasa malu. 
b. Rasa malu terhadap Allah, yaitu kesadarannya bahwa Tuhannya senantiasa mengetahui perbuatannya. Dia selalu mengawasi dan memperhatikan dirinya, apakah dia dalam kesendirian atau berada di tengah-tengah orang banyak. Baik dia dilihat oleh orang atau tidak dilihat, dia tetap merasakan bahwa Allah selalu berada di sampingnya, melihat dan mengawasinya, sehingga dia merasa malu kepada-Nya, dan meninggalkan perbuatan yang kurang baik.

\section{Cara Melestarikan Rasa Malu}

Jalan untuk melestarikan rasa malu itu antara lain :

a. Setiap orang hendaknya menyadari apa yang mereka katakan dan mereka lakukan. Sehingga tidak keluar darinya sesuatu yang bertentangan dengan rasa malu, yang menyebabkan orang lain lebih berani bertindak kepadanya. Misalnya, hendaknya dia tidak mengucapkan kata-kata kotor ketika ada anak kecil, tidak berbohong, dan tidak mengingkari janji. Hal ini dilakukan dalam rangka mengupayakan tumbuhnya rasa malu pada diri anak-anak.

b. Jika dia melihat orang lain berkata atau berbuat yang tidak senonoh dan sedikit rasa malunya, maka hendaknya dia mengatakan bahwa hal itu tidak baik. Di samping itu hendaknya dia memberikan peringatan kepada pelakunya agar perbuatan itu tidak terulang kembali. Misalnya, omongan kotor ketika seseorang bertemu dengan temannya, khususnya ketika dia sedang dalam keadaan marah.

c. Jika dia melihat orang merasa malu, karena ucapan atau perbuatannya, maka hendaknya dia memujinya, atau memberanikan orang tersebut agar dia tetap mempertahankan perilaku seperti itu.

Berdasar hal tersebut di atas, jika ketiganya dapat dijaga, maka setiap kali ada hal yang merangsang nafsu syahwat, atau ada film-film porno, maka hal itu sudah barang tentu akan berpengaruh langsung kepada rasa malu yang dimiliki oleh masyarakat.

\section{Kesimpulan}

Dalam perspektif islam, anak merupakan amanah (titipan) Allah SWT yang harus dijaga, dirawat, diberikan kasih sayang, dipelihara dengan sebaik-baiknya oleh setiap orang tua. Menurut Imam Al-Ghazali metode melatih anak merupakan perkara yang terpenting dan paling utama. Sejak lahir, anak telah diberikan potensi yang dapat dikembangkan sebagai penunjang kehidupannya di masa depan. Bila anak dilatih untuk 
mengerjakan kebaikan, ia akan tumbuh menjadi orang yang baik dan bahagia di dunia dan di akhirat. Bila potensi-potensi ini tidak diperhatikan, pada nantinya anak akan mengalami hambatan-hambatan dalam pertumbuhan maupun perkembangannya.

Cara orang tua menjaga anaknya adalah dengan mendidik dan mengajarkan akhlak yang baik serta menjaganya dari perilaku buruk lingkungan sekitar anak. Apabila anakanak telah menunjukkan tanda-tanda dan mampu membedakan antara yang baik dan buruk, maka orang tua harus terus meningkatkan pengawasannya kepada anak. Bila anak mulai muncul rasa malu dan memiliki rasa segan, serta tidak mau melakukan beberapa hal tertentu, dengan begitu anak sudah mulai bisa berpikir dengan baik sehingga mengetahui perkara yang tidak baik dan anak mulai malu untuk melakukan hal-hal yang tidak baik tersebut.

Orang tua atau pendidik hendaknya memprioritaskan pendidikan agama yang berorientasi kepada akhirat sebagai bekal untuk anak-anaknya sebelum memberikan pendidikan formal yang berorientasi keduniawian. Orang tua sudah semestinya mendampingi anak-anaknya ketika berada di rumah maupun diluar rumah. Oleh sebab itu dalam Islam mewajibkan semua orang tua agar menjadi teladan baik bagi anaknya. Lebih mendalami sumber utama ajaran Islam yaitu Alquran dan hadits dengan membaca tafsirtafsir atau buku-buku keislaman lainnya sebagai tuntunan dalam kehidupan sehari hari dalam mendidik anak.

\section{Daftar Pustaka}

Abdullah, M. A. 2002. Antara al Ghazali dan Kant: Filsafat Etika Islam, (Terj), Hamzah, Bandung, Cet.1, Mizan.

Alatas, A. 2004. Remaja Gaul Nggak Mesti Ngawur, Jakarta: Hikmah.

Alim, Nur. 2011. Pendidikan Seks Bagi Remaja Dalam Islam. http://zona99.blogspot.com/2011/11/pendidikan-seks-bagi-remaja-menurut.html, diakses pada tanggal 09 April 2012.

Al-Isfihani, al-Raghib. 2001. Al-Mufradat fi Garib al-Qur'an, Bairut; Dar al-Ma'rif.

Al-Marogi, Ahmad Mustofa., Tafsir Al Marogi, Mustofa al-Babi al-Habibi, Mesir, Juz 51394 $\mathrm{H} / 1974 \mathrm{M}$ 
Amrillah. 2006. Perilaku Seksual Wabal Di Tinjau Dari Kualitas Komunikasi Orang TuaAnak Tentang Seksualitas, Skripsi, Surakarta: UMS.

Andriyani, A. 1996. Konsep Diri, Harga Diri dan Kepercayaan Diri Remaja, Jurnal, No. 2, Remaja.

Ar-Rifa'i, Muhammad Nasib, Tafsir Ibnu Katsir, Maktabah Ma'arif, Riyadh, 1410 H/1989 M

Ashraf, A. 1993. Horison Baru Pendidikan Islam, Pustaka Firdaus.

Atun, dkk. 2004. IMS atau Penyakit Kelamin, dalam Kesehatan Reproduksi Remaja, Kerjasama Jaringan Khusus Kesehatan untuk Anak Jalanan Perempuan di Yogyakarta, bersama PKBI-DIY. Yogyakarta.

Azwar, S. 2003. Sikap Manusia Teori dan Pengukurannya, Yogyakarta: Pustaka Pelajar. 2003. Penyusunan Skala Psikologi, Yogyakarta, Pustaka Pelajar, hlm 30-38.

Basyir, A. A. 1996. Ajaran Islam tentang Pendidikan Seks, Hidup Berumah Tangga Pendidikan Anak, Bandung : PT Al Warif.

Bukhari, M. 1994. Islam dan Adab Seksual, Bumi Aksara, Jakarta.

Chaplin, J. P. 1981. Kamus Lengkap Psikologi, (Edisi Revisi), Jakarta: PT Raja Grafindo Persada.

Daradjat, Z. 2010. IImu Jiwa Agama, Jakarta, cet 17, Bulan Bintang.

------------. 2010. Remaja Harapan dan Tantangan, Jakarta: Bulan Bintang.

Departemen Agama Republik Indonesia. 1979. Pola Pembinaan Mahasiswa IAIN. Jakarta: IAIN.

Departemen Pendidikan dan Kebudayaan. 1986. Kamus Besar Bahasa Indonesia, Jakarta, Edisi II, Balai Pustaka.

Djarot,M. S. 1993. Seks dalam Islam. Bandung: Sinar.

Djazuli \& Aen, N. 2000. Ushul Fiqh, Metodolgi Hukum Islam. Jakarta, PT. Raja Grafindo Persada.

Dianawati, A. 2003. Pendidikan Seks Untuk Remaja. Depok, Kawan Pustaka.

Finjari, A. S. A. 1996. Nilai Kesehatan dalam Syariat Islam. Jakarta: Bumi Aksara. 
F.J., A.M.P.Knoers Monks \& Haditono, S. R. 2001. Psikologi Perkembangan Pengantar Dalam Berbagai Bagiannya, Yogyakarta: Gajah Mada University Press.

Ensiklopedi Indonesia. t.t. (Bandung: N.V. Penerbitan W. Van Hoeve).

Eriyani, L. Dwi. 2009. Kesehatan Reproduksi Remaja: Menyoal Solusi, disampaikan pada Seminar Nasional Seksualitas dan Kesehatan ReproduksiRemaja di PP. Nuris, Jember-Jawa Timur.

Gerungan, W.A.. 1986. Psikologi Sosial. Bandung: Eresco.

Ghazali, Imam Abu Hamid Muhammad bin Muhammad. t.t. Ihya' 'Ulumiddin, Semarang: Karya Putra, Juz 1.

Ghazali, Imam Abu Hamid Muhammad bin Muhammad. t.t. Ihya' 'Ulumiddin, Semarang: Karya Putra, Juz 3.

Ghazali, A. t.t. Ayyuh al-Walad. Surabaya: Toko Kitab al-Hidayah.

Ghazali, A. 1969. Ihya' al Ghazali, Jilid I, Surabaya, Cet. 4, Faizan.

Gunarsa, S. 1987. Psikologi Anak Bermasalah, Jakarta: Gunung Mutiara.

Habsjah, dkk.Peranan Ayah vis-a-vis lbu dan Pranata Sosial LainnyadalamPendidikanSeks Remaja.The Population Council and The Atma Jaya Research Centre,Jakarta. 1995.

Hafidhuddin, Didin, Dakwah Aktual, Jakarta, Cet.1, Gema Insani Press, 1998

Hurlock,E.B., Psikologi Perkembangan,Jakarta : Erlangga,Edisi 6,Jilid 2,Alih Bahasa Meitasari Tjandrasa, 1990

Hurlock,E.B., Psikologi Perkembangan Suatu Pendekatan Sepanjang Rentang Kehidupan, Alih Bahasa Istiwidayanti \& Soedjarwo, Jakarta: Erlangga,1999

Husein, Muhamad, TarbiyatulAulad fil- Islam, Dar-dakwah, Cetakanke 2, Alexandria Egypt, 2007

Ibnu Manzur, Abi al-Fadl Jamal al-Din Muhammad bin Mukram. Lisan al-Arab, Jilid IX, Bairut: Dar al-Fikr,1990

Irsyady, Kamran As'ad Al Ghazali Menggapai Hidayah, Yogyakarta : Pustaka Sufi, 2003 
Istanti,Surviani, Membimbing Anak Memahami Masalah Seks; Panduan Praktis untuk Orang Tua, Bandung : Pustaka Ulumuddin,2004

Kartono, Kartini , PsikologiPerkembangan Anak, Bandung : Mandar Maju,1999

Kementerian Agama RI, al-Qur'an dan Tafsirnya, jilid 3, PT Sinergi Pustaka Indonesia, Jakarta, 2012

Khisbiyah, dkk. Kehamilan tak Dikehendaki di Kalangan Remaja,Pusat PenelitianKependudukan Universitas GadjahMada, Yogyakarta. 1996.

Kompas.com, 14/03/12.

Krech,David, dkk, Psikologi Sosial, Palembang: Universitas Sriwijaya,1982

Ma'lus Luis. Al-Munjid fi al-Lughah wa al-Alam, tt

Mappiare,A., Psikologi Remaja, Surabaya: Usaha Nasional,1982

Mar’at, Sikap Manusia Perubahan Serta Pengukuran, Jakarta: Ghalia Indonesia, 1982

Monks, F.J.- A.M.P. Knoers, Siti Rahayu Haditono.,Psikologi Perkembangan Pengantar Dalam Berbagai Bagiannya,Yogyakarta: Gajah Mada University Press,2001

Muslih, TB. Aat Syafaat \& Sohari Sahroni. Peranan Pendidikan Agama Islam Dalam

Mussen, Paul Henry, dkk., Perkembangan dan Kepribadian Anak, Jakarta: Arcan,1994

Mu'tadin, Zainun. Pendidikan Seks Pada Remaja.www.e-psikologi.com.2013

Nafis, Cholil, Fiqih Keluarga, Jakarta: Mitra Abadi Press, 2009

Najati, Muhammad 'Utsman, Jiwa dalam pandang Filosof Muslim, Terj. Gazi Saloom, Cet. I, Bandung : Pustaka Hidayah, 2002

Nawawi, Muhammad bin Umar An, Syarah Uqudul Lujain Fi Huquuqiz Zaujain, Surabaya : Al-Hidayah, tth

Nugraha,Boyke Dian, Remaja dan Problem Seks, Jakarta : Pustaka Kartini, 1995

Okezone.com, 28/3/2012.

Pratiwi, Niken, Pendidikan Sex Bagi Anak Dalam Islam, http://zillamoslem.multiply.com/journal/item/125/Pendidikan Seks Untuk Anak Dala m Islam diakses pada tanggal 09 April 2012 
Purwanto, Ngalim, IImu Pendidikan, Jakrta : Remadja Karya,1927

Qardhawi, Yusuf. Halal dan Haram dalam Islam. Surabaya: PT Bina Ilmu.1980

Qudsi, Hasan El, Ketika anak bertanya tentang seks, Solo : Tinta Medina, 2012

Quesem, Etika al Ghazali, Bandung: Pustaka, 1998

Rachman (ed.) Kontekstualisasi Doktrin Islam dalam Sejarah, Jakarta: Paramadina, 1994

Rasyidi, A. Rahmat, Islam Problem Seks, Kehamilan dan Melahirkan, Bandung : Angkasa, 1993

Rifa'i, Islah al, Ihya li al Ghazali,Kairo, Markaz al-Ahram li al-Tarjamah wa al-Nasr, 1998

R,L. Atkinson, Dkk.Pengantar Psikologi, Jilid II, Jakarta : Erlangga,1999

Rusy, Abidin Ibnu , Pemikiran al Ghazali Tentang Pendidikan,Yogyakarta, Cet.1Pustaka Pelajar, 1998

Al Ghazali dan Plato, Surabaya, cet.1, Bina IImu, 1986

Sabiq, Sayyid, Fiqih Sunnah (trjm), Bandung, PT Al-Ma'arif, jilid 6, 1980

Santrock, J.W.,Adolescence : Perkembangan Remaja, Jakarta, ed.6, Erlangga,2003 , Life-Span Development, Jakarta, jilid.2 Erlangga,2002

Sarwono, Sarlito.W., Psikologi Remaja, Cet.3, Ed. I, Jakarta: PT Raya Grafindo Persada, 2002

, Pergeseran Norma PerilakuSeksual Kaum Remaja: Sebuah Penelitian

Terhadap Remaja, Jakarta, Jakarta: CV Rajawali, 1981

Shahid,Athar, Bimbingan Seks bagi Kaum Muda. Pustaka Zahra: Jakarta, 2004

Soerjono Soekamto, Sosiologi Suatu Pengantar, (Jakarta: CV Rajawali), 1984

Soetjiningsih, Tumbuh Kembang Remaja dan Permasalahannya, Jakarta : Sagung Seto,2004

Sulaiman, Fathiyah Hasan., Konsep Pendidikan Al-Ghazali, P3M

Sulistyo, Rono, Pendidikan Seks, Bandung : Elstar Offset, tth

Sunarto, Nyi Agung Hartono, Perkembagan Peserta Didik, Jakarta : Rieneka Cipta, 2008 
Suraji dan Sofia Rahmawatie. Pendidikan Seks bagi Anak: Panduan Keuarga Muslim. Pustaka Fahima: Yogyakarta,2008

Surtiretna, Nina, Bimbingan Seks Bagi Remaja, Bandung : Remaja Rosdakarya, 2000 - Remaja dan Problema Seks Tinjauan Islam dan Medis, Bandung: Remaja Rosdakarya, 2006

Surur, Thaha Abdul Baqi, Imam Al Ghazali Hujjatul Islam,Jakarta : Pustaka Mantiq, tth Syeh Al Imam As Syarif Al Hamam Al 'Alim Ar Rabbani, Qurrotul 'Uyuun, Semarang: AlUluwiyyah, th.

TB. Muslih, dkk., Peranan Pendidikan Agama Islam Dalam Mencegah Kenakalan Remaja (Juvenile Delinguency), Jakarta:Rajawali Pers, 2008

Thalib, M., Memahami 20 Sifat Fitrah Anak, Bandung: Irsyad Baitus Salam, 1995

TimMitra Inti.MitosSeputar Masalah Seksualitas dan Kesehatan Reproduksi,YayasanMitra Inti.Jakarta. 2009.

Tukan, Johan Suban, Pendidikan Seksualitas(Bunga Rampai), Yayasan Hidup Katolik dan PKK-KAJ, 1984

Ulwan ,Abdullah Nashih., Tarbiyatu Al-Aulad Fi Al-Islam, Darussalam, Baerut, 1979

Usman, Abd Karim., Sirat Al-Ghazali, Maktabah Al-Nahdhah, Mesir, 1964

Vivanews.com, 28/09/12.

Wahab Zuhaili, Tafsir Munir Fil Aqidah Wasy Syari'ah Manhaj, juz XVIII, (Beirut: Dar al Fikr al-Masukkan'asir, t.t), hlm. 210.

Walgito,B., Psikologi Sosial: Suatu Pengantar, Yogyakarta : Andi Offset,1991

Widyastuti, Yani dkk. 2009.Kesehatan Reproduksi. Fitramaya. Yogyakarta.

Iman, Chandra Hayatul., Hasil wawancara pribadi dengan Wakil Rektor III, 10 Oktober 2014

Zainuddin, dkk.,Seluk Beluk Pendidikan Dari al Ghazali, Jakarta: Bumi Aksara, 1991. 